4 Johnson RD, Davidson S, Saunders JB, Williams R. Fractures on chest radiography as indicators of alcoholism in patients with liver disease. $B M$ 1984;288:365-6.

5 Johnell $\mathrm{O}$, Kristenson $\mathrm{H}$, Redlund-Johnell I. Lower limb fractures and registration for alcoholism. Scand 7 Soc Med 1985;13:95-7.

6 Cooper C, Parker DJP, Morris J, Briggs RS. Osteoporosis, falls, and age in fracture of the proximal femur. $B M \mathcal{H}$ 1987;295:13-5.

7 Seeman E, Melton LJ 3rd, O'Fallon WM, Riggs BL. Risk factors for spinal osteoporosis in men. Am F Med 1983;75:977-83.

8 Saville PD. Changes in bone mass with age and alcoholism. $f$ Bone foint Surg $[\mathrm{Am}]$ 1965;47:492-9.

9 Rico H. Alcohol and bone disease. Alcohol Alcohol 1990;25:345-52.

10 Laitinen K, Valimaki M. Alcohol and bone. Calcif Tissue Int 1991;49(suppl): S70-3.

1 Laitinen $\mathrm{K}$, Valimaki $\mathrm{M}$, Keto $\mathrm{P}$. Bone mineral density measured by dualenergy X-ray absorptiometry in healthy Finnish women. Calcif Tissue Int (in press).

12 Angus RM, Sambrook PN, Pocock NA. Dietary intake and bone mineral density. Bone Miner 1988;4:265-77.

13 Hansen MA, Overgaard K, Riis BJ, Christiansen C. Potential risk factors for development of postmenopausal osteoporosis examined over a 12-year development of postmenopausal osteoporosis

14 Stevenson JC, Lees B, Devenport M, Cust MP, Ganger KF. Determinants of bone density in normal women: risk factors for future osteoporosis? $B M$ 1989;298:924-8.

15 Hall ML, Heavens J, Cullum ID, Ell PJ. The range of bone density in normal

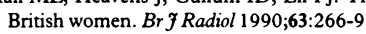

16 Criqui MH, Barrett-Connor E, Austin M. Differences between respondents and non-respondents in a population-based cardiovascular disease study. Am J Epidemiol 1978;108:367-72.
17 Henry RJ, Chiamori N, Golub OJ, Berkman S. Revised spectrophotometric methods for the determination of glutamic-oxalacetic transaminase and lactic dehydrogenase. Am f Clin Pathol 1960;34:381-98.

18 Jones BR, Barrett-Connor E, Criqui MH, Holdbrook MJ. A community study of calorie and nutrient intake in drinkers and nondrinkers of alcohol. $\mathrm{Am} \mathcal{f}$ Clin Nutr 1982;35:135-9.

19 Barrett-Connor E, Suarez L. A community study of alcohol and other factors associated with the distribution of high density lipoprotein cholesterol in older vs. younger men. $A m \mathcal{F}$ Epidemiol 1982;115:888-93.

20 Greenland $\mathrm{S}$. The effect of misclassification in the presence of covariates. $\mathrm{Am}$ Epidemiol 1980;112:564-9.

21 Bjorneboe G-EA, Bjorneboe A, Johnsen J, Skylv N, Oftebro H, Gautvik KM et al. Calcium status and calcium-regulating hormones in alcoholics. Alcoholism 1988;12:229-32.

22 Laitinen K, Valimaki M, Lamberg-Allardt C, Kivisaari L, Lalla M, Karkkainen $\mathrm{M}$, et al. Deranged vitamin D metabolism but normal bone mineral density in Finnish noncirrhotic male alcoholics. Alcoholism 1990;14: 551-6.

23 Johnell $O$, Nilsson BE. Bone mineral content in men with fractures of the upper end of the femur. Int Orhop 1984;7:229-31.

24 Harding A, Dunlap J, Cook S, Mattalino A, Azar F, O'Brien M, et al Osteoporotic correlates of alcoholism in young males. Orthopedics 1988;11: 279-82

25 Gavaler JS, Love K, Ortega CT. An international study of the relationship between alcohol consumption and postmenopausal estradiol. In: Khalant $\mathrm{H}_{3}$ Khanna JM, Israel Y, eds. Advances in biomedical alcohol research: proceedings of the 5th ISBRA/RSA congress. Oxford: Pergamon Press, 1991:327-30.

(Accepted 23 March 1993)

\title{
Risk assessment adjusted for gestational age in maternal serum screening for Down's syndrome
}

\author{
Jason Gardosi, Max Mongelli
}

\section{Abstract}

Objective-To investigate the relation between errors in calculation of gestational age and assessment of risk of Down's syndrome and to analyse the implications for screening programmes.

Design-Retrospective analysis of dating of gestational age by menstrual history $v$ ultrasound scan. Computer program with maternal age and concentrations of $\alpha$ fetoprotein and free $B$ human chorionic gonadotrophin to calculate risk for a range of expected dates of delivery. Computer simulated prospective application of new screening programme.

Setting-Teaching hospitals in Nottingham.

Subjects-31561 women with singleton pregnancies with gestational age based on routine ultrasound scan. Computer simulation of 20000 women in three age ranges (up to 37 ; up to 40 ; all).

Main outcome measures-Distribution of error between gestational age based on ultrasound scan $v$ menstrual history. Proportion of women in the population who require precise dating of pregnancy; proportion of women who require amniocentesis.

Results-With gestational age derived from ultrasound scan as reference the $95 \%$ confidence interval for gestational age by menstrual history was -27 to +9 days. A screening programme for Down's syndrome for women up to age $\mathbf{4 0}$ would yield a low risk $(<1: 250)$ for this range of days in $86.0 \%$ of cases. The $14.0 \%$ of women remaining would have one or more high risk values in their report and would thus require an ultrasound scan for precise dating of the pregnancy; $30 \%$ of these-that is, $3.7 \%$ of the screened population-would be identified as high risk and require consideration for amniocentesis.

Conclusions-Screening programmes for Down's syndrome require the facility for precise dating of pregnancy to improve the accuracy of risk assessment. This can be achieved without introducing additional scans for early dating in the whole population but by selecting only those cases (about $14 \%$ ) when an error in dates is likely to affect the risk of Down's syndrome.

\section{Introduction}

Biochemical screening to determine the risk of Down's syndrome in all pregnancies has been advocated ${ }^{\prime}$ and is being introduced in most health districts in the United Kingdom. ${ }^{2}$ Normal values for the biochemical analytes such as human chorionic gonadotrophin and $\alpha$ fetoprotein vary considerably with gestational age, and correct dates are required to make the result accurate. ${ }^{3} \mathrm{~A}$ recent attempt to establish population screening in Nottingham, relying on dating by mentrual history, was soon abandoned because of confusion caused by false positive test results from wrong dates, which led to a threefold rise in referrals for amniocentesis during the last quarter of 1991.

Most maternity units check the menstrual dates at the time of a routine scan for structural anomaly of the fetus at 18-19 weeks' gestation. The recommended time for the serum test for Down's syndrome is earlier, at about 16 weeks, which also allows the simultaneous assessment of $\alpha$ fetoprotein as an additional screen for neural tube defects. This means that the pregnancy dates have often not been checked by ultrasonography by the time the risk of Down's syndrome is reported, and it has therefore been suggested that an earlier scan is required to date all pregnancies for purposes of screening. ' This would have considerable logistical and financial implications, quite apart from the cost of the serum test itself. We investigated how the method of risk assessment could be improved without having to resort to routine, early scan dating of all pregnant women.

\section{Subjects and methods}

To examine the relation between the risk of Down's syndrome and gestational age a computer program was written (Turbo Pascal, Borland International, California) to calculate risk over a range of days before and after a given gestational age derived from the date of the last menstrual period at the time of the blood sample. Coefficients for the variables considered relevant in a particular population can be entered. In this program we multiplied the risk related to maternal 


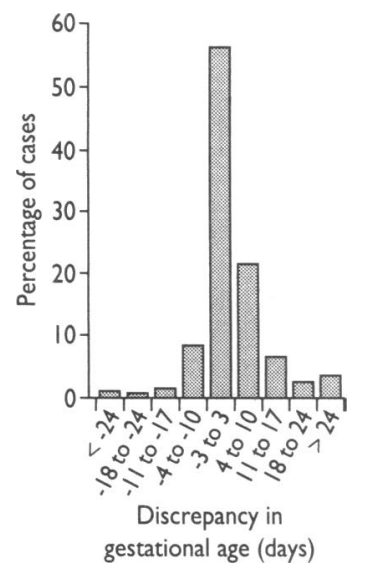

FIG 1-Discrepancy between gestational ages according to menstrual history and ultrasound $\operatorname{scan}(n=28755)$

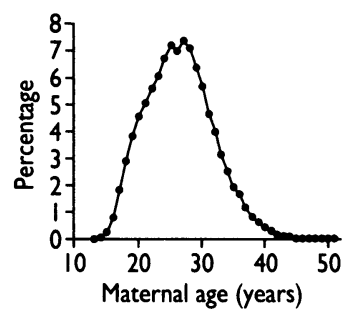

FIG 2-Distribution of maternal age in Nottingham ( $n=31561)$

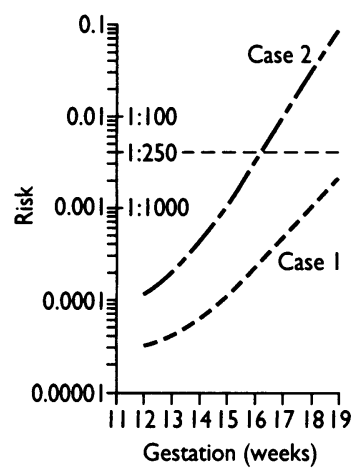

FIG 3-Risk of Down's syndrome $v$ gestational age for two women. Case 1 -maternal age $26, \beta$ human chorionic gonadotrophin $13 \cdot 8 I U / /$, $\alpha$ fetoprotein $33.7 \mu \mathrm{g} / \mathrm{l}$ (representing median values); case 2-age 34.2, $\beta$ human chorionic gonadotrophin 20.7IU/, $\alpha$ fetoprotein $19 \cdot 8 \mu g /$ age at delivery ${ }^{4}$ by an odds modifier based on a bivariate Gaussian frequency distribution ${ }^{5}$ by using published values for $\alpha$ fetoprotein and free $\beta$ subunit of human chorionic gonadotrophin. ${ }^{67}$ The program can calculate expected date of delivery from the given last menstrual period and can print out a report with a range of expected delivery dates and corresponding values of risk of Down's syndrome.

We used data from 31561 computer files of pregnancies dated by ultrasound from the Nottingham obstetric database to determine the frequency distribution for maternal age in this population. Of this dataset, 28755 files had complete menstrual records and were analysed to assess discrepancy between dating by menstrual history and ultrasonography before 20 weeks' gestation.

A computer simulation model was designed to test our risk programme and its implications for screening. Random numbers, generated with Wichman and Hill's algorithm, ${ }^{8}$ were used to obtain normally distributed $z$ values according to the von Neuman rejection method. ${ }^{9}$ The $\mathrm{z}$ values were transformed according to published data $^{7}$ to the appropriate, multiple of median concentrations for $\beta$ human chorionic gonadotrophin and $\alpha$ fetoprotein specific for gestational age. Values for maternal age and when appropriate adjustments for gestational age were obtained as integers from our local cumulative frequency distribution. The output of each module was analysed with statistical software ${ }^{10}$ to ensure conformity with the published distributions. Each simulation was run for 20000 cases with an IBM compatible 486DX personal computer.

\section{Results}

Figure 1 shows the discrepancy between gestational ages derived by ultrasonography and menstrual history in our population. For $21.5 \%$ of pregnancies scan dates were outside plus or minus 7 days from dates based on

TABLE I-Risk of having baby with Down's syndrome based on values of $\alpha$ fetoprotein and $\beta$ human chorionic gonadotrophin at 16 weeks for two women, for a range of delivery dates calculated from $95 \%$ confidence interval for date of last menstrual period

\begin{tabular}{lcc}
\hline & \multicolumn{2}{c}{ Risk of Down's syndrome } \\
\cline { 2 - 3 } Expected date & Case 1 & Case 2 \\
of delivery & $1: 1674$ & $1: 38$ \\
& $1: 1866$ & $1: 44$ \\
29 Dec 92 & $1: 2080$ & $1: 52$ \\
30 Dec 92 & $1: 2317$ & $1: 61$ \\
31 Dec 92 & $1: 2580$ & $1: 72$ \\
1 Jan 93 & $1: 2870$ & $1: 85$ \\
2 Jan 93 & $1: 3191$ & $1: 100$ \\
3 Jan 93 & $1: 3544$ & $1: 117$ \\
4 Jan 93 & $1: 3932$ & $1: 137$ \\
5 Jan 93 & $1: 4357$ & $1: 161$ \\
6 Jan 93 & $1: 4821$ & $1: 188$ \\
7 Jan 93 & $1: 5325$ & $1: 220$ \\
8 Jan 93 & $1: 5873$ & $1: 257$ \\
9 Jan 93 & $1: 6466$ & $1: 299$ \\
10 Jan 93 & $1: 7104$ & $1: 348$ \\
11 Jan 93 & $1: 7789$ & $1: 404$ \\
12 Jan 93 & $1: 8521$ & $1: 467$ \\
13 Jan 93 & $1: 9300$ & $1: 540$ \\
14 Jan 93 & $1: 10125$ & $1: 621$ \\
15 Jan 93 & $1: 10996$ & $1: 714$ \\
16 Jan 93 & $1: 11909$ & $1: 817$ \\
17 Jan 93 & $1: 12863$ & $1: 933$ \\
18 Jan 93 & $1: 13854$ & $1: 1061$ \\
19 Jan 93 & $1: 14878$ & $1: 1204$ \\
20 Jan 93 & $1: 15930$ & $1: 1361$ \\
21 Jan 93 & $1: 17005$ & $1: 1532$ \\
22 Jan 93 & $1: 18096$ & $1: 1719$ \\
23 Jan 93 & $1: 19198$ & $1: 1922$ \\
24 Jan 93 & $1: 20303$ & $1: 2140$ \\
25 Jan 93 & $1: 21403$ & $1: 2374$ \\
26 Jan 93 & $1: 22492$ & $1: 2623$ \\
27 Jan 93 & $1: 23560$ & $1: 2887$ \\
28 Jan 93 & $1: 24600$ & $1: 3164$ \\
29 Jan 93 & $1: 25603$ & $1: 3753$ \\
30 Jan 93 & $1: 26563$ & $1: 4063$ \\
31 Jan 93 & $1: 27471$ & $1: 4379$ \\
1 Feb 93 2 Feb 93 & $1: 28320$ & \\
3 Feb 93 & & \\
\hline & & \\
\hline & & \\
\hline
\end{tabular}

menstrual dates. The distribution was skewed: in $17 \cdot 6 \%$ (that is, $82 \%$ of cases when the discrepancy was at least a week) the menstrual dates tended to overestimate the age of gestation. With ultrasonographic dating as reference, the $95 \%$ confidence interval for gestational age derived from menstrual history was -27 to +9 days. The median maternal age at booking in our population was 26 (interquartile range 22-29) years, and $7 \cdot 2 \%$ of women were age 35 or over (fig 2 )

Figure 3 shows the likelihood of Down's syndrome on a logarithmic axis plotted against a range of gestational ages for two illustrative samples (table I). The lower curve shows risk $v$ gestation for a woman of median age (26) and values for $\beta$ human chorionic gonadotrophin (13.8 IU/l) and $\alpha$ fetoprotein $(33.7 \mu \mathrm{g} /$ L), which represent the respective medians for 16 weeks' gestation. For the whole range of calculated gestational ages the risk value never exceeds $1: 250$. In contrast, possible results for a $34 \cdot 2$ year old woman with a $B$ human chorionic gonadotrophin of $20.7 \mathrm{IU} /$ and $\alpha$ fetoprotein of $19.8 \mu \mathrm{g} / \mathrm{l}$ is shown on the second curve, which is upwardly displaced and has a steeper slope. At 16 weeks this combination of variables represents 1.5 and 0.6 multiples of median for $B$ human chorionic gonadotrophin and $\alpha$ fetoprotein, respectively, and gives a risk value of almost $1: 250$. If this serum sample had been taken at 14 weeks, the risk of Down's syndrome would be $<1: 1000$ whereas at 18 weeks the odds would be $>1: 100$. For a given last menstrual period (here 1 April 1992) the program calculates the expected date of delivery (7 January 1993) plus a range of dates corresponding to the $95 \%$ confidence interval for menstrual dates (that is, -27 to +9 days). Against each of these dates the risk of Down's syndrome is listed as a ratio.

Table II lists the results of the computer simulation for different age ranges for the screened population (to 37 ; to 40 ; all) and for two cut off levels for defining "high risk" (1:250 and 1:100). The proportions of reports are shown which would either contain only low risk (that is, be a negative report) or have at least one high risk value within the calculated range of expected delivery dates (which constitutes an indication for dating by scan). The proportion of women who will have an actual high risk of having a baby with Down's syndrome after the correct dates are established and thus require consideration for amniocentesis is shown in the right column.

\section{Discussion}

The association between gestational age and risk of Down's syndrome and the error caused by wrong dates may often be overlooked or underestimated. A policy of correcting menstrual dates by ultrasound measurements if the discrepancy is more than 17 days either way has been used in a recent screening programme.' Our analysis suggests that such a tolerance is too wide; the combination of input variables - that is, analyte assay results and maternal age-can cause the risk $v$ gestation curve (fig 3 ) to be shifted upwards and have a steeper slope, making precise establishment of the correct dates mandatory. Selective scanning of women with positive results may miss affected cases,' but this can be avoided by assessing the risk of Down's syndrome for the full range of dates which represent the likely error in dates based on menstrual history.

The pitfalls of using purportedly certain menstrua dates are well known and the error is greatest in the younger age groups, ${ }^{11}$ which represent the bulk of a screening programme. The magnitude of error in menstrual dates in our population and the heavily skewed distribution agree with observations from a smaller sample ${ }^{12}$ and highlight the need to use ultrasound as reference. An early scan is already indicated for 
TABLE II-Computer simulated results of screening programme for Down's syndrome in 20000 singleton pregnancies

\begin{tabular}{lcccc}
\hline $\begin{array}{l}\text { Cut off for } \\
\text { high risk }\end{array}$ & $\begin{array}{c}\text { Age range } \\
\text { screened }\end{array}$ & $\begin{array}{c}\text { Proportion of } \\
\text { women with low risk } \\
\text { reports (\%) }\end{array}$ & $\begin{array}{c}\text { Proportion for whom } \\
\text { ultrasound scan } \\
\text { dating required (\%) }\end{array}$ & $\begin{array}{c}\text { Proportion offered } \\
\text { amniocentesis (\%) }\end{array}$ \\
\hline \multirow{3}{*}{$1: 250$} & $<37$ years & $87 \cdot 4$ & $12 \cdot 6$ & $3 \cdot 5$ \\
& $<40$ years & $86 \cdot 0$ & $14 \cdot 0$ & $3 \cdot 7$ \\
$1: 100$ & All ages & $85 \cdot 8$ & $14 \cdot 2$ & $4 \cdot 6$ \\
& $<37$ years & $94 \cdot 7$ & $5 \cdot 3$ & 0.9 \\
& $<40$ years & $94 \cdot 4$ & $5 \cdot 6$ & $1 \cdot 1$ \\
& All ages & $94 \cdot 3$ & $5 \cdot 7$ & $1 \cdot 3$ \\
\hline
\end{tabular}

uncertain menstrual dates, poor obstetric history, or threatened miscarriage. But most pregnancies in the United Kingdom are not scanned until 18-19 weeks, which has been shown to be the optimum time to screen for developmental abnormalities. ${ }^{1314}$ This scan usually also serves to confirm or correct the expected date of delivery. The introduction of earlier scans to date each pregnancy for purposes of screening for Down's syndrome would still require the later scan to ensure reliable screening for structural anomalies.

Even ultrasound dating may introduce error in risk assessment if weeks are rounded off and given as integers. ${ }^{15}$ In our method this is avoided by calculating a whole range of gestational ages, representing the $95 \%$ confidence interval for date by menstrual history in this population, which are then expressed as a list of likely delivery dates. By determining the risk factor specific to gestation for each of these dates two possible categories are identified in which the report would be issued. For the overwhelming majority of cases the risk of Down's syndrome is low for the whole range of likely delivery dates. For example, if the screening programme includes all women under 40 and the agreed cut off for high risk is $1: 250,86 \%$ of women could be reassured by their general practitioner or community midwife as soon as the report is received without a dating scan having been performed (table II). The remaining $14 \%$ of reports will have at least one high risk value for the given range of dates, and only these women will require early referral for a dating scan. These women need not be alarmed but told that the correct gestational age needs to be established before the risk for Down's syndrome can be read with any accuracy. This approach is justified as only $3 \cdot 7 \%$ of these $14 \%$ of cases (table II) - that is, less than a third -will actually end up with a high risk value adjusted for gestational age and would be offered amniocentesis.

Our predicted rates of amniocenteses are similar to those which were obtained in two recent demonstration projects. ${ }^{16}$ But all cases in our system would be identified with the benefit of dates adjusted by scan. We believe that this method will increase the detection rate of Down's syndrome, a hypothesis which we intend to test prospectively.

On the report the risk of Down's syndrome can be printed out categorically as high and low or expressed as a numerical likelihood ratio, which clinicians may prefer for purposes of counselling. Figure 4 gives an example of a possible format in which a computer report could be issued. If the dates have to be revised after the scan there is no need to refer back to the laboratory as the clinician will usually find the new risk value within the range of dates listed on the report.

In $5 \%$ of all cases the actual gestational age will by definition fall outside our stated confidence interval for menstrual dates. In cases when the error is towards overestimation of the actual gestation no high risk patients would be missed as the risk values within the reported range would also be high, thus already indicating early referral for a dating scan. At the other extreme, for the $2.5 \%$ of women with a grossly underestimated gestational age, the computer simulation predicts that $37.5 \%$ of these (that is, an additional
FIG 4-Possible format for reporting screen result for woman represented by Case 2 in fig 3
$0.9 \%$ of the screened population) would require a dating scan before interpretation of the result was possible. As the corrected expected delivery date would not be within the range of those initially reported this group would require a new risk to be calculated by the laboratory. The discrepancy of dates may not become obvious until the time of the routine anomaly scan, which means that fewer than $5 \%$ of women in this subgroup - that is, $0.1 \%$ of the screened population-would experience delay in being offered an amniocentesis.

Although there is as yet no general agreement on the type and number of analytes to use for screening for Down's syndrome, there seems to be evidence that the free $B$ subunit of human chorionic gonadotrophin improves sensitivity and that conjugated oestriol offers little in addition to $\alpha$ fetoprotein and $B$ human chorionic gonadotrophin. ${ }^{17}{ }^{18}$ Combined screening for Down's syndrome and neural tube defects on the same blood sample taken at around 16 weeks is becoming technically easier. ${ }^{19}$ Both results are dependent on gestational age and could be reported together in this manner. Reducing error in gestational dating will improve detection rates in a screening programme for Down's syndrome. ${ }^{314}$ Our method promises to achieve this by identifying those cases which require early scanning for correct assessment of risk, without the logistical and financial burden of additional dating scans for the whole population.

We thank Mr Mark Wilcox for supplying frequency distributions for maternal age and length of gestation from the Nottingham computerised obstetric database.

1 Wald NJ, Kennard A, Densem JW, Cuckle HS, Chard T, Butler L. Antenata maternal serum screening for Down's syndrome: results of a demonstration maternal serum screening for
project. $B M$ I $^{1}$ 1992;305:391-4.

Cuckle H. Screening for Down's syndrome. BMY 1992;305:1504

3 Wald NJ, Cuckle HS, Densem JW, Kannard A, Smith D. Materna serum screening for Down's syndrome: the effect of routine ultrasound scan determination of gestational age and adjustment for maternal weight. Br f Obstet Gynaecol 1992;99:144-9.

4 Cuckle HS, Wald NJ, Thompson SG. Estimating a woman's risk of having a pregnancy associated with Down's syndrome using her age and serum alpha-fetoprotein level. Br J Obstet Gynaecol 1987;94:387-402.

5 Reynolds TM, Penney MD. The mathematical basis of multivariate risk screening, with special reference to screening for Down's syndromeassociated pregnancy. Ann Clin Biochem 1989;27:452-8.

6 Spencer K. Evaluation of an assay of the free beta-subunit of choriogonadotrophin and its potential value in screening for Down's syndrome. Clin Chem 1991:37:809-14.

7 Spencer K, Coombes EJ, Mallard AS, Ward AM. Free beta human choriogonadotropin in Down's syndrome screening: a multicentre study of its role compared with other biochemical markers. Ann Clin Biochem 1992;29: 506-18.

8 Wichman BA, Hill ID. An efficient and portable pseudo-random number generator. Applied Statistics 1982;31:188-90

9 Von Neuman J. Various techniques used in connection with random digits. National Bureau of Standards Applied Mathematics 1951;12:36-8.

10 SPSS. Statistical package for the social sciences-PC+. Chicago, Illinois: SPSS, 1988.

11 Geirsson RT. Ultrasound instead of last menstrual period as the basis of gestational age assignment. Ultrasound in Obstetrics and Gynecology 1991;1: $212-9$

12 Waldenstroem U, Axelson O, Nilsson S. A comparison of the ability of sonographically measured biparietal diameter and the last menstrual period to predict the spontaneous onset of labour. Obstet Gynecol 1990;76:336-8.

13 Saari-Kemppainen A, Karjalainen O, Ylostalo O, Heinonen OP. Ultrasound screening and perinatal mortality: controlled trial of systematic one-stage screening in pregnancy. Lancet 1990;336:387-91.

14 Chitty LS, Hunt GH, Moore J, Lobb MO. Effectiveness of routine ultrasonography in detecting fetal structural abnormalities in a low risk population. BMF 1991;303:1165-9.

15 Reynolds TM, Penney MD, Hughes $\mathrm{H}$. Ultrasonographic dating of pregnancy causes significant errors in Down syndrome risk assessment that may be minimalized by use of biparietal diameter-based means. $\mathrm{Am} \mathcal{J} \mathrm{Obste}$ Gynecol 1992;166:872-8.

16 Haddow JE, Palomaki GE, Knight GJ, Williams J, Pulkkinen A, Canick JA, et al. Prenatal screening for Down's Syndrome with use of maternal serum markers. N Engl f Med 1992;327:588-93.

17 Macri N , Kasturi RV, Krantz DA, Cook E, Moore N, Young J, et al. Maternal serum Down's screening: free beta protein is a more effective marker than human chorionic gonadotropin. Am $\mathcal{O}$ Obstet Gynecol 1990; 163:1248-53.

18 Spencer K, Coombes EJ, Mallard AS, Ward AM. Free beta human choriogonadotropin in Down's syndrome screening: a multicentre study of its role compared with other biochemical markers. Ann Clin Biochem 1992;29: 506-18.

19 Macri JN, Spencer K, Andersan R. Dual analyte immonoassay-a new approach to neural tube defect and Down's syndrome screening. Ann Clin Biochem 1992;29:390-6.

(Accepted 8April 1993) 